\title{
Editorial
}

\section{PROBLEMS AND OPPORTUNITIES IN THE THERAPY OF LEPROSY}

We now have a useful range of antileprosy drugs from which to choose, and the two chief problems confronting the clinician are the side effects of these drugs and the emergence of drug resistant strains of Mycobacterium leprae.

\section{Side effects of antileprosy drugs}

Here we are concerned not only with direct effects of the drug in use but also with indirect effects in the form of reactional states (lepra reactions). As regards direct side effects, and taking dapsone first, the chief advantage of this drug (apart from its low cost) is its relative lack of toxicity. Haemolytic anaemia is the most important side effect, and interest centres on dapsone's capacity to induce haemolysis in persons who are deficient in glucose-6-phosphate dehydrogenase (G6PD). On the face of it one would expect haemolytic anaemia to be a troublesome complication in the management of leprosy, but this is not so for it is rarely encountered even in populations with the highest incidence of enzyme deficiency-Africans and those with African ancestry. One explanation lies in the fact that different types of G6PD deficiency predominate in different ethnic groups; for example, the African type is characterized by a mild enzyme deficiency, the Mediterranean type by severe deficiency, and variations are present in East and South-East Asia (W.H.O. Chronicle, 1974). Another explanation is that the dosage of dapsone generally employed today (700 $\mathrm{mg} /$ week or less) is below the level likely to induce haemolysis of clinical significance. Clofazimine (Lamprene; B663) is a safe drug to use but has the disadvantage of causing unsightly skin pigmentation, especially in persons with light skins, and it is doubtful if this side effect will ever be overcome because of the nature of the dye and its tendency to be selectively deposited in leprosy lesions by macrophages. I have a patient who stopped clofazimine therapy 5 years ago but is still embarrassed by slate coloured markings on his face. Serious side effects of rifampicin, of which liver damage is the most important, have been recorded in the treatment of tuberculosis when this antibiotic has been given in interrupted dosage such as twice a week, but can be much reduced by regular daily dosage, so much so that it can now be said that "liver toxicity with rifampicin does not seem to be a major problem." (Leading Article, 1973). Thiambutosine (Ciba, 1906) is unique in being devoid of direct side effects.

Turning to the indirect side effects of antileprosy drugs we come to the subject of reactional states-the leprologist's bugbear. Although lepra reactions were known before the introduction of effective therapy, the incidence has increased with the advent of the sulphone group of drugs in the 1940's, and it has since become apparent that other effective antileprosy drugs also have a reaction- 
producing capacity. Waters and Helmy, in their paper in the present Number of this Journal, demonstrate that ENL reaction in lepromatous leprosy (type 2 reaction) is not directly due to dapsone but is consequent upon the killing of leprosy bacilli, and the next stage in research on this subject will be to explain the mechanism whereby dead bacilli trigger a rapid change in cell-mediated immunity (CMI) in borderline leprosy (type 1 reaction) and an immune complex syndrome in lepromatous leprosy. Are lepra reactions dosage dependent? In other words, is high dosage of dapsone more likely than low dosage to precipitate them? This is a question of great concern to clinicians, for it is natural for them to presume that larger dosage increases the rate of destruction of leprosy bacilli and thereby increases the incidence of reaction. In fact, many clinicians over the past two or three decades have gained a strong impression that the incidence and severity of lepra reactions are dosage dependent. However, a preliminary trial in lepromatous patients at Sungei Buloh, Malaysia, has failed to confirm this impression (Pearson and Helmy, 1973), and further controlled trials on this important subject are indicated.

Two drugs require special mention on this question. The first is clofazimine (Lamprene; B663), a drug which combines an antileprosy effect as good as that of dapsone with an anti-inflammatory action capable of controlling some manifestations of lepra reaction, and the point of special importance is dosage. The odd situation is that one capsule of $100 \mathrm{mg}$ twice a week, while being an effective therapeutic dose, is useless in controlling lepra reaction (and, in fact, can precipitate it), whereas larger dosage in the region of one capsule two to four times a day can control it. The other drug is rifampicin. There were fears, when it was introduced into the treatment of leprosy, that its rapid bactericidal effect against Myco. leprae might result in a high incidence of lepra reaction, but this has not been borne out by subsequent experience. Although this may be explained by the rate of release of intracellular antigens of Myco. leprae, a more likely explanation is immunosuppression as rifampicin has been shown to have an immunosuppressive effect, not only in man and animals, but also in vitro as judged by experiments on human lymphocytes which have demonstrated its inhibiting action on (1) blastic stimulation by phytohaemagglutinin, and (2) the secretion of migration-inhibiting factor (Serrou, 1974).

\section{Resistance to antileprosy drugs}

Sulphones. The incidence of sulphone resistance in lepromatous leprosy is undoubtedly increasing, and attention focuses on two aspects of sulphone therapy: low dosage and irregularity of treatment. On the first point a decision has to be made on what constitutes low dosage, and so far this has not been made. Most leprologists appear to accept dosages in the region of $100 \mathrm{mg} /$ week as low, but this I would not accept. In my opinion dosages of $5 \mathrm{mg} /$ day $(35 \mathrm{mg} /$ week) or less should be considered low, and this is an important question requiring attention. The paper by Gelber et al. in the present Number of this Journal supports the contention that low dosage is a factor in causing sulphone resistance, but on the other hand there has been no report of relapse of lepromatous leprosy in patients receiving an injection of DADDS (Hansolar; acedapsone) regularly every 75 to 77 days, a dosage which liberates only $2.4 \mathrm{mg}$ of dapsone into the tissues daily. The fact that there have been relapses of lepromatous leprosy a year or more after stopping DADDS injections has nothing to do with dosage as relapses can occur in patients who stop taking $100 \mathrm{mg}$ daily. In support of the 
view that irregularity of treatment encourages sulphone resistance we have the report of Jacobson and Trautman (1971) who recorded a high incidence in lepromatous patients who had been irregular on treatment; there was no question of any of these patients taking low dosage of sulphone. In my own experience I have not encountered sulphone resistance in lepromatous patients taking $5 \mathrm{mg} /$ day regularly and from the beginning of treatment, but have a number of patients who developed resistance on $100 \mathrm{mg} / \mathrm{day}$; they all had been irregular on treatment and had suffered one or more relapses after stopping treatment against medical advice. This aspect of the problem requires more research, as does the proposition of combating drug resistance by giving dapsone in combination with another antileprosy drug. Although this would seem the most logical approach it is doubtful if combined therapy will prove practicable in developing countries because of expense.

Other antileprosy drugs. It is generally accepted that drug resistance in lepromatous leprosy develops after two to three years of treatment with thiambutosine (Ciba, 1906) and thiacetazone (TB1), but so far there have been no reports of resistance to clofazimine or to rifampicin.

\section{Immunotherapy}

On the basis that the poor prognosis in lepromatous leprosy is due to depression of cell-mediated immunity (CMI) against Myco. leprae, whereas the good outlook for cure in tuberculoid leprosy is due to the possession of CMI, research is now in progress on the possibility of transferring cellular immunity to lepromatous patients by injecting lymphocytes or extracts from leucocytes (transfer factor) derived from tuberculoid patients or from healthy donors hypersensitive to lepromin. The first attempt at this line of treatment was reported by Bullock et al. (1972) and a number of centres are now developing it, but it is still in the experimental stage. All that can be said at the present time is that it holds out great promise for the lepromatous patient and marks an important stage in the better understanding of leprosy and its management.

\section{References}

Bullock, W. E., Fields, J. P. and Brandriss, M. W. (1972). Transfer factor as immunotherapy for lepromatous leprosy. New Eng. J. Med. 287, 1053.

Jacobson, R. R. and Trautman, J. R. (1971). The treatment of leprosy with the sulfones. Faget's original 22 patients. A thirty-year follow-up on sulfone therapy for leprosy. Int. J. Lepr. 39, 726.

Leading Article (1973). Rifampicin or ethambutol in the routine treatment of tuberculosis. $B r$. med. J. 4, 568 .

Pearson, J. M. H. and Helmy, H. S. (1973). The effect of stopping dapsone treatment for two months and then restarting it in full dosage in patients with moderately severe erythema nodosum leprosum. Lepr. Rev. 44, 75.

Serrou, B. (1974). Lancet 2, 172.

W.H.O. Chronicle (1974). Pharmacogenetics-the influence of heredity on the response to drugs. $28,25$.

W. H. Jopling 